\title{
Sustainable Information and Communication Technology (ICT) for Sustainable Data Governance in Nigeria: A Narrative Review.
}

\author{
Felix. C. Aguboshim ${ }^{1} \quad$ Irene. N. Ezeasomba $^{1} \quad$ Joy. E. Ezeife ${ }^{2}$ \\ 1.Principal Lecturer at Federal Polytechnic Oko, Department of Computer Science, Oko, Nigeria \\ 2.Lecturer, at Federal Polytechnic Oko, Department of Computer Science, Oko, Nigeria
}

\begin{abstract}
Recent developments in big data have heightened the need for Sustainable Data Governance (SDG). SDG is significant in realizing sustainable economic development in Nigeria. Information and Communication Technologies (ICTs) have made landmark innovational trends in empowering data governance globally. Despite these global impacts of ICT on data governance, numerous investigations have shown that poor sustainability of ICT in Nigeria poses barriers that impede progress related to data governance. SDG which is the pivot for economic growth has remained relatively nonexistence or unattended to due to corrupt policies and practices, ignorance, and illiteracy that plagued sustainable ICT innovations in Nigeria. For this study, the Unified Theory of Acceptance and Use of Technology (UTAUT) was adopted as the conceptual framework. UTAUT model claims that the benefits of using technology and the factors that drive users' decision to use it, is what determines users' acceptance behavior. In this study, the authors explored a narrative review, analysis, and synthesis of prior research that focused on the theoretical underpinnings of vast works of literature that revealed significant information on the impact of sustainable ICT on Sustainable Data Governance in Nigeria. The authors also extracted peer-reviewed articles within the last five years from electronic databases, using some keywords such as "ICT and SDG", "ICT and national economic development", "Trends for ICT", etc. The result of this study revealed that strict adherence to policies, laws, and guidelines on the adoption of ICT coupled with good formulation and communication of same, are the major impact of sustainable ICT that can leverage SDG in Nigeria. The result from this study may increase understanding, minimize corrupt practices and encourage trust in ICT innovations, ICT adoption, its acceptance and sustainability that can positively impact SDG and national economic development in Nigerian.
\end{abstract}

Keywords: ICT, Sustainable Data Governance, adoption, sustainability, Trends, Trust, corruption.

DOI: $10.7176 /$ JIEA/9-5-02

Publication date: August $31^{\text {st }} 2019$

\section{Introduction}

Organization data are becoming complex and sophisticated, and data management solutions on their own are becoming very expensive and unable to cope with the reality of ever-increasing data complexity. One of the best ways to solve the data problem is the implementation of effective data governance. "Data Governance is a system of decision rights and accountabilities for information-related processes, executed according to agreedupon models which describe who can take what actions with what information, and when, under what circumstances, using what methods" (The Data Governance Institute, 2015, p.1).

Data Governance is of concern to any individual or group or Data Stakeholders who have an interest in how data is created, collected, processed and manipulated, stored, made available for use, or retired. According to The Data Governance Institute (2015), organizations need to move from informal governance to formal Data Governance when one of four situations occurs: (a) The organization gets so large that traditional management isn't able to address data-related cross-functional activities. (b) The organization's data systems get so complicated that traditional management isn't able to address data-related cross-functional activities. (c) The organization's Data Architects, SOA teams, or other horizontally-focused groups need the support of a crossfunctional program that takes an enterprise (rather than siloed) view of data concerns and choices. (d) Regulation, compliance, or contractual requirements call for formal Data Governance.

Data governance approach driven by IT will fail because it adopted rigid and fragmented processes that were carried out on a system by system basis, and lacked a good structure and the wider support of the organization (The Data Governance Institute, 2015). Data governance is all about realizing that data are the asset to the nation's business, and making sure that all the rules, policies, roles, responsibilities and tools needed are put in place to ensure that data are accurate, consistent, complete, available and secure (Koltay, 2016). ICT can be simply defined as the physical devices and infrastructures used for the collection, storage, processing, and disseminating of all forms and formats of data and information, and the required platforms or means for the transmission and disseminating of same (Oladimeji \& Foltyn, 2018; Olise, 2010 ). The global aim of data governance is to encourage a single version of the truth and to allow one single reference for critical master data, across geographies and business units. SDG is of significant importance in realizing or attaining sustainable national economic growth in Nigeria. A significant relationship exists between sustainable ICT and sustainable 
data governance (Bennett, 2017).

On the other hand, Sustainable ICT is what defines sustainable data governance (Oladimeji \& Foltyn, 2018), and occupies a significant key position in leveraging sustainable data governance (Olise, 2010). The value placed on any technological innovation is measured by its adoption, acceptance, and sustainability (Hoffman, Singh, \& Prakash, 2015). Sustainable ICT, therefore, plays an important role in SDG tasks (Oladimeji \& Foltyn, 2018). This is because ICT is a major enabler of SDG (Toyo \& Ejedafiru, 2016). Despite the significant importance of ICT technological innovations in Nigeria, its poor adoption, usage, and sustainability, worsened by corrupt practices, is ravaging virtually every system in the nation, especially SDG and national economic growth.

\subsection{Problem Statement}

Data governance is ICT driven and can only be meaningful when it aligns with the ICT policies, rules, goals, and values in a sustainable manner. Our purpose in this study was to identify the challenges of sustainable ICT that negatively impact sustainable data governance and economic development in Nigeria. The general IT problem postulated in this study was the poor performance or sustainability of the SDG majorly due to corrupt practices and policies that have hindered proper adoption, usage, and sustainability of ICT in Nigeria. The specific IT problem is that some ICT policies, laws, guidelines, and value system on the adoption and sustainability of ICT coupled with formulation and communication of same, do not favor SDG because such policies and practices are rendered impotent by corrupt practices, ignorance, illiteracy, and a bad economy.

\subsection{Research Question}

What are ICT policies, laws, guidelines and value system strategies used by policymakers to sustain ICT innovations to leverage SDG?

\section{Literature Review}

The aim of data governance is far-fetched in Nigeria because its enabler (ICT) is not adequately valued, adopted or used. This is because it takes sustainable ICT to achieve SDG (Koltay, 2016). The value, adoption, and use of ICT are measured by its sustainability. Users are motivated to use ICT based on their perceived level of trust, perceived ease of use and easy-to-use (Aguboshim \& Miles, 2019). Therefore, failure to value and use ICTs can undermine even the strongest data governance policies, because what contributes to non-sustainable ICT innovations has proven to cause or be related to non-sustainable data governance (Toyo \& Ejedafiru, 2016). Sustainable ICT technological innovations have significant importance in leveraging SDG (Bennett, 2017). Researchers also have identified major key determinants of sustainable ICT as content and functional value that interacts positively to affect its sustainability and the implementation of appropriate policies and guidelines that mediate significantly in users to impact sustainable technology (Olise, 2010). Other determinants of sustainable ICT are perceived value and provision of security facilities that significantly influence its enablement for SDG (Aguboshim, \& Udobi, 2019).

In Nigeria, corrupt policies and practices, ignorance, illiteracy, and the bad economy appear to be the major factors militating against sustainable ICT. Policy measures, laws, and infrastructures required to handle ICT sustainability are rather relegated to the background. Implementation and adherence to policies control over policy enforcement, and enterprise definitions are no longer reliable or efficient in sustaining ICT innovations due to corrupt practices in Nigeria. Technological innovations in Nigeria have been made to be attitudinal, thereby rendering its sustainability impotent. Human adherence to required principles and policies for the adoption of ICTs has been claimed by a significant number of empirical researches as the major links the ICT sustainability, while the negligence of same constitutes a great risk to the ICT sustainability (Oladimeji \& Foltyn, 2018; Olise, 2010; Toyo \& Ejedafiru, 2016). Violations of established ICT policies and safeguards by users especially by some of our so-called honorable men in our society have led to poor sustainable data governance and diversified economy.

\subsection{Conceptual Framework}

The Unified Theory of Acceptance and Use of Technology (UTAUT), proposed by Venkatesh, Morris, Davis, \& Davis (2003) was adopted as the conceptual framework for this study. UTAUT model claims that the benefits of using technology and the factors that drive users' decision to use it, is what determines users' acceptance behavior. The theory considers factors: user adoption behaviour toward intention to use ICT, and users' usage behaviour of ICT. Both user adoption and usage of ICT are affected by four constructs: performance expectancy (PE), effort expectancy (EE), social influence (SI), and facilitating conditions (FC), and four moderators: gender, age, experience and voluntariness of use. UTAUT model in recent times has been widely adopted (Oye, AIahad, \& Abrahim, 2014). UTAUT was adopted as our theoretical foundation to study ICT sustainability for sustainable data governance, and the pros and con of its consumerization implications. 


\subsection{Tools for Sustainable Data Governance (SDG).}

Leaders of successful data governance programs declared in December 2006 at the Data Governance Conference in Orlando, FL, that data governance is between 80 and 95 percent communication (Hopwood, 2008). Many of the objectives of Data Governance programs are accomplished within appropriate ICT tools. Clearly, data governance is not a typical IT project but driven by appropriate ICT tools. SDG is exemplified by sustainable ICT policies that are designed to (a) simplify and make more efficient decision making with minimized asymmetric information, (b) automate many intangible activity connected with SDG, (c) collect, process and use large data sets of various formats obtained from many sources require for sustainable SDG, (d) provide immediate and very cheap communication protocols, (e) launch new sales and dissemination channels (ecommerce) for SDG, and distribute same products as well, and (f) creating new business models and virtual entrepreneurship for sustainable SDG. The use of ICT has changed the way we work, rest, buy, travel, interact and so on, which in turn translates into the functioning of enterprises and societies including functional and SDG.

\section{Methodology}

A narrative review approach was adopted in this study to review significant information based on the study conceptual framework, existing systems that enhance ICT sustainability. We also reviewed, analyzed and synthesized prior research findings. According to Hill and Burrows (2017), a narrative review is adopted where analysis and synthesis of different and related research findings are required to draw holistic interpretations or conclusions based on the reviewers' own experience, existing theories, and models. In this paper, we adopted a narrative methodology and explicitly explained the methodological commitments of narrative inquiry. We also made our search criteria and the criteria for inclusion explicit by including in our review process, keywords and term identification, article identification, quality assessment, data extraction, and data synthesis. Methodological triangulation has been defined as the use of multiple sources of data to gain multiple perspectives, maximize reliability and validation of data and build coherent justification of data interpretation that relates to the study case or phenomenon (Durif-Bruckert, et al., 2014). We adopted methodological triangulation to ensure the reliability and validity of data, and justification of interpretations from the reviews.

\section{Data Collection}

We reviewed the research findings that are relevant and related to our study. Many of such findings came from the ProQuest databases, ScienceDirect, Walden University international library databases and peer-reviewed, and other related texts. We also used phrases and terms as key search words in the databases for related literature on ICT sustainability for SDG in Nigeria. Such phrases and terms included ICT sustainability, ICT innovational Trends, Sustainable Data Governance, ICT threats, cyber-attacks and security, major determinants of ICT and Data Governance sustainability, and many others. Our reviews incorporated 29 references. Ninety three percent (93\%) of total references incorporated in the study is peer-reviewed, while (76\%) are peer-reviewed journals that are within the last 5 years.

\section{Analysis and Synthesis of Prior Research}

No one, single, "one size fits all" approach to data governance exist (Brous, Janssen, \& Vilminko-Heikkinen, 2016). Rather, data governance formats in an organization are often peculiar and specific to such organization (Brous, et al., 2016), with outlined organization roles, decision areas, responsibilities, and a unique outlay of specialized personnel that are hired, trained, nurtured, and integrated into the organization (Khatri \& Brown, 2010; Otto, 2011). Based on the proposed initial frameworks for data governance by some researchers, and the attendant influencing structural factors, four data governance key concepts or principles have emerged: (a) Organization, which included Decision rights (Thompson, Ravindran, \& Nicosia, 2015), Balanced roles (AlKhouri, 2012), Stewardship (Thompson, et al., 2015), Ownership (Al-Khouri, 2012), Separation of duties and concern (Malik, 2013), and Improved coordination of decision making (Otto, 2011). (b) Alignment, that involved Meeting business needs (Dawes, 2010), Aligning business and IT (Tallon, 2013), Developing data strategy (Malik, 2013), Defining data quality requirements (Otto, 2011), Reducing error of use (Panian, 2010), and Effective policies and procedures (Hripcsak, et al., 2014).

(c) Compliance Monitoring and Enforcement, concerned with Accountability (Kim, et al., 2014; Thompson, et al., 2015), Policy enforcement (Tallon, 2013), Due diligence (Hripcsak, et al., 2014), Privacy (Al-Khouri, 2012), Openness (Kim, et al., 2014), Security (Al-Khouri, 2012), data quality measurement (Hripcsak, et al., 2014), and (d) Common Understanding, based on Shared data commons (Al-Khouri, 2012; Otto, 2011), Use of standards and Metadata management (Khatri \& Brown, 2010; Otto, 2011; Thompson, et al., 2015), Standardized data models and operations(Otto, 2011; Thompson, et al., 2015), and Facilitate communication (Malik, 2013).

Recently, relevant and wide varieties of important literature have identified ICT as an important innovationenablers of sustainable data governance, cloud computing, big data, and other mobile and internet dependent 
interfaces (Oladimeji \& Foltyn, 2018). Despite the implementation of ICT innovations in Nigeria, sustainable SDGs have remained weak and vulnerable. This is because there is evidence that suggests that corrupt practices and non-adherence to policies and rules are increasingly exploiting ICT sustainability, and adversely affecting SDG. Reasons for non-sustainable ICT that adversely affected SDG included problems associated with corrupt policies and poor usability of ICT systems, and not placing required value to ICT by users (GreavuSerban \& Serban, 2014), and limited perception of the usefulness and ease of use of ICT innovations (Aguboshim \& Miles, 2019).

As mentioned above, the major reasons for this might be corruption, ignorance, and illiteracy. This claim is supported by UNDP statistical report that revealed the fact that $14 \%$ of Nigerian adults considered corruption as the major significant challenges militating against sustainable ICT in Nigeria (UNDP, 2016). There is a need for awareness and training in the country for people to understand and be able to perceive available technological innovations as useful and easy-to-use. This may bring about sustainable ICT that will leverage economic development and social change.

Other contributing factors to what might be the possible significant challenges of sustainable ICT have been classified into four groups by Dwivedi, et al. (2015): (a) management of ICT processes, policies and guidelines, (b) literacy level of ICT users and how it impacts usage and adoption, (c) well defined ICT project size, goals, performance, robustness, and implementation, and (d) technology failures resulting from ICT use and misuse. On the other hand, Ho, Hsu, and Yen (2015) suggested three major strategies or skills to improve or manage ICT adoption, usage, and sustainability: (a) adherence to usability guidelines and policies, (b) process control, and (c) information and data transmission and dissemination.

\section{Discussions and Conclusions}

ICT projects in Nigeria are failing, despite much enthusiasm and optimism and global trend for ICT and its significant importance for SDG. Despite these global trends for ICT, the adoption of technology solutions in Nigeria has remained relatively slow due to corruption, ignorance, illiteracy, and the bad economy (Toyo \& Ejedafiru, 2016). Why is ICT not making maximum impact in Nigeria as observed in other African countries? These are a few of our observations:

\subsection{The value placed on Technology by the Government.}

The contribution of any technological innovation can only be realized when and if the technology is widely diffused and used. The value placed on any technological innovation is measured by its adoption, acceptance, and sustainability. It is hypocritical to observe that the various arms of the Government make much noise about ICT while in truth they do not value it because they do not see ICT services as a means to sustainable data governance and economic productivity of the nation. ICT is seen more like a "corruption-exposer" technology.

\subsection{Inadequate and Incomplete Implementation of ICT}

Most technological innovations in Nigeria lack solid and proper implementations because they often end with IT leaving off "information and communication" aspect of ICT. Technological innovations must involve "information and communication", to employ the databases instead of databanks. For instance, traffic lights in Nigeria are not properly implemented and so are not adequately or properly put to use. Nigeria is about the only country where cameras are mounted on the traffic light with no corresponding machinery to adequately capture, document and book or fine offenders. One cannot run ICT without good documentation, storage, and communication. How can you run an automated traffic system without proper data governance and documentation of vehicles and their owners?

Instead, we observe policemen and other touts being used to check traffic light offenders, when the traffic lights are embedded or supposed to be embedded with monitoring cameras. What a waste of resources. The same is applicable to other establishments such as NRSC, Police, Ministry of Justice, etc. Our ICTs are not adequately implemented or used. The non-sustainability of ICT in Nigeria is the major reason for a nonsustainable diversified economy and low economic growth in Nigeria. If our diversified economic ventures including data governance are not using the ICT effectively, its sustainability is crossly endangered, especially now that ICT innovations are widely integrated into ambient or ubiquitous environments.

\subsection{Corrupt Practices and Policies.}

Corruption appears to be the major hindrances to sustainable ICT for maximum SDG in Nigeria. Technology does not have an attitude or designed to exhibit attitudinal behaviors. Attitudes comprise of three components: emotions, behaviors, and thoughts. ICTs are not designed to have emotions, behaviors, and thoughts, but to operate according to the specified programs and protocols. When ICT innovations are subjected and corrupted with human emotions, behaviors, and thoughts, they become useless, un-impactful and their outputs nonsensical including the SDG that it intended to leverage. Some instances: (a) the so-called honorable men in the society 
breaking the traffic light. (a) Using the exit door for an entrance. (c) Using their vehicles with Government registration numbers even when they have left the office, and (d) Some Nigerians, because they in the police, army, and others, you do not need to renew their vehicle particulars because the so-called ICT in place has been subjected to have attitudinal behavior. This is a big slap on the face of technology in Nigeria. This is the major hindrances of sustainable ICT for maximal SDG in Nigeria. Embracing technological innovations in Nigeria would mean embracing transparency, which exposes corruption and enforces maximal SDG.

\subsection{High Cost of Running Technology Dependent Organizations}

The Internet and regular electricity supply are good facilitators and enablers of technology-dependent projects. In Nigeria, the cost of the Internet is very high when compared to other countries, especially western countries. Electricity supply is also very expensive, even though its supply is neither regular nor predictable. Also, the high cost of running a technology dependent organization has made SDG farfetched in Nigeria. This has also reduced the probability of releasing any technological hits including SDG.

\subsection{The Way Forward}

ICT innovations are now handled with better interconnected and interdependent facilities because connectivity is widely integrated into ambient or ubiquitous environments through an intuitive interface or "smart" interaction. The way forward to overcome the hindrances of SDG is to ensure the effectiveness in the implementation of sustainable ICT. The following are recommended: (a) ICT and data governance stakeholders in Nigeria must recognize and understand the significant importance of sustainable ICT to SDG, and communicate same to both the literate, semi-literate and illiterate groups. (b) Existing ICT infrastructures, its usability, procurement and implementation for sustainability goals must be reviewed, and a new system designed to meet the required standards for SDG. (c) There is a need for the adoption of ICT international standards in all facets of the Nigeria education and legal system for standardized behaviors and values towards sustainable ICT. (d) To fully actualize a sustainable ICT that will effectively leverage sustainable diversified economy, all Nigerians, irrespective of rank or status should learn to respect the law rather than the persons. ICT innovations, SGD in particular, are being slaughtered on the platform of corruption and lawlessness.

\section{Conclusion}

This paper conducts an evidenced-based study using Web content analysis that substantiates the current state of data governance in Nigeria. When ICTs are fully implemented in all required sectors and systems, Nigeria may start to reap the dividends of SDG and economic growth as witnessed in the developed nations with the best ICT facilities. Issues and challenges of ICTs in Nigeria should be given urgent and top priority attention in the national assembly and bills passed on the effective use of ICT for sustainable SDG and economic development in Nigeria, powered by electricity supply that is stable.

\section{References}

Aguboshim, F. C., \& Miles, G. S. (2019). Engaging pictorial images and voice prompts interface design strategy to create easy to use banking ATM system interfaces in Nigeria. Journal of Information Engineering and Application (JIEA), 8(1), 1-14. doi:10.7176/jiea/8-1-01

Aguboshim, F. C., \& Udobi, J. I. (2019).Security issues with mobile IT: A Narrative Review of Bring -YourOwn-Device (BYOD). Journal of Information Engineering and Application (JIEA), 9(1), 56-66. doi:10.7176/jiea/8-1-070

Al-Khouri, A. M. (2012). Data Ownership: Who Owns 'My Data'? International Journal Of Management \& Information Technology, 2(1), 1-8. doi:10.24297/ijmit.v2i1.1406

Bennett, S. (2017). What is information governance and how does it differ from data governance? Governance Directions, 69(8), 462-467.

Brous, P., Janssen, M., \& Vilminko-Heikkinen, R. (2016). Coordinating Decision-Making in Data Management Activities: A Systematic Review of Data Governance Principles. Book Chapter published 2016 in Lecture Notes in Computer Science, 115-125. doi:10.1007/978-3-319-44421-5_9

Dawes, S. S. (2010). Stewardship and usefulness: Policy principles for information-based transparency. Government Information Quarterly, 27(4), 377-383. doi:10.1016/j.giq.2010.07.001

Durif-Bruckert, C., Roux, P., Morelle, M., Mignotte, H., Faure, C., \& Moumjid-Ferdjaoui, N. (2014).Shared decision-making in medical encounters regarding breast cancer treatment: the contribution of methodological triangulation. European Journal of Cancer Care, 24(4), 461-472. doi:10.1111/ecc.12214

Dwivedi, Y., Wastell, D., Laumer, S., Henriksen, H. Z., Myers, M. D., Bunker, D., ... Srivastava, S. C. (2015). Research on information systems failures and successes: Status update and future directions. Information Systems Frontiers, 17(1), 143-157. doi:10.1007/s10796-014-9500-y

GreavuSerban, V., \& Serban, O. (2014). Social Engineering a General Approach. Informatica Economica, 18(2), 
5-14. doi:10.12948/issn14531305/18.2.2014.01

Hill, C., \& Burrows, G. (2017). New voices: The usefulness of a narrative approach to social work research. Qualitative Social Work: Research and Practice, 16(2), 273-288. doi:10.1177/1473325017689966

Ho, L., Hsu, M., \& Yen, T. (2015). Identifying core control items of information security management and improvement strategies by applying fuzzy DEMATEL. .Information and Computer Security, 23(2), 161177. doi:10.1108/ics-04-2014-0026

Hoffman, D. D., Singh, M., \& Prakash, C. (2015).The Interface Theory of Perception Psychonomic. Bulletin \& Review, 22(6), 1480-1506. doi:10.3758/s13423-015-0890-8

Hopwood, P. (2008). "Data Governance: One Size Does Not Fit All". DM Review Magazine. Archived from the original on 2008-10-02. Retrieved 2008-10-02. At the inaugural Data Governance Conference in Orlando, Florida, in December 2006

Hripcsak, G., Bloomrosen, M., Brennan, P. F., Chute, C. G., Cimino, J., Detmer, D. E., ... Safra, C. (2014). Health data use, stewardship, and governance: ongoing gaps and challenges: a report from AMIA's 2012 Health Policy Meeting. Journal of the American Medical Informatics Association, 21(2), $204-211$. doi:10.1136/amiajnl-2013-002117

Khatri, V., \& Brown, C. V. (2010). Designing data governance. Communications of the ACM, 53(1), 148-152. doi: $10.1145 / 1629175.1629210$

Kim, K. K., Browe, D. K., Logan, H. C., Holm, R., Hack, L., \& Ohno-Machado, L. (2014). Data governance requirements for distributed clinical research networks: triangulating perspectives of diverse stakeholders, Journal of the American Medical Informatics Association, 21(4), 714-719. doi:10.1136/amiajnl-2013002308

Koltay, T. (2016).Data governance, data literacy and the management of data quality. International Federation of Library Associations and Institutions, 42(4), 303-312.

Malik, P. (2013). Governing Big Data: Principles and practices. IBM Journal of Research and Development, 57(3/4), 1-13. doi:10.1147/jrd.2013.2241359

Oladimeji, T. T., \& Foltyn, G. B. (2018). ICT and Its Impact on National Development In Nigeria: An Overview. Research \& Reviews: Journal of Engineering and Technology, 7(1), 1-10.

Olise, F. P. (2010). Information and Communication Technologies (ICTs) and Sustainable Development in Africa: Mainstreaming the Millennium Development Goals (MDGs) into Nigeria's Development Agenda. $J$ SocSci, 24(3): 155-167.

Otto, B. (2011). Organizing Data Governance: Findings from the Telecommunications Industry and Consequences for Large Service Providers. Communications of the Association for Information Systems, 29(1), 45-66. doi:10.17705/1 cais.02903

Oye, N. D., AIahad, N., \& Abrahim, N. (2014).The history of UTAUT model and its impact on ICT acceptance and usage by academicians. Education and Information Technologies. 19(1), 251-270.

Panian, Z. (2010). Some practical experiences in data governance. World Academics Journal of Engineering Sciences, 38(1), 150-157. doi:10.15449/wjes

Tallon, P. P. (2013). Corporate Governance of Big Data: Perspectives on Value, Risk, and Cost. Computer, 46(6), 32-38. doi:10.1109/mc.2013.155

The Data Governance Institute (2015). Definitions of Data Governance.Retrieved April 9, 2019 from : $\mathrm{http}: / / \mathrm{www}$.datagovernance.com/adg data governance definition/.

Thompson, N., Ravindran, R., \& Nicosia, S. (2015). Government data does not mean data governance: Lessons learned from a public sector application audit. Government Information Quarterly, 32(3), 316322. doi:10.1016/j.giq.2015.05.001

Toyo, O. D., \& Ejedafiru, F. E. (2016). Utilization of Information and Communication Technologies (ICTs) for Sustainable Economic Development in Nigerian. International Journal of Ergonomics and Human Factors, 12(2), 22-34.

UNDP (2016). UNDP Nigeria 2016 Annual Report Compiled and edited by Lucky Musonda. UNDP Nigeria 2016 Annual Report_web.pdf. Retrieved from http://www.ng.undp.org/content/dam/nigeria/docs/CO\%20Docs/UNDP\%20Nigeria\%202016\%20Annual\%2 0Report_web.pdf

Venkatesh, Morris, Davis, \& Davis. (2003). User Acceptance of Information Technology: Toward a Unified View. MIS Quarterly, 27(3), 425. doi:10.2307/30036540 